\title{
CORRESPONDENCE
}

We welcome letters to the Editor concerning articles which have recently been published. Such letters will be subject to the usual stages of selection and editing; where appropriate the authors of the original article will be offered the opportunity to reply.

Letters should normally be under 500 words in length, double-spaced throughout, signed by all authors and fully referenced. The edited version will be returned for approval before publication.

\section{VARIABILITY IN COBB ANGLE MEASUREMENTS}

Sir,

We wish to comment on the article in the September 1995 issue entitled 'Variability in Cobb angle measurements in children with congenital scoliosis' by Loder et al (1995; 77-B:768-70). About 90 methods of measurement have been described to qualify the deformity in scoliosis (Capasso 1992). Evaluation based on only one of these variables is not reliable because angular measurement only partially defines a spinal curve. There are a number of possible errors in measuring scoliosis and the accuracy of the different methods varies (Capasso, Maffulli and Testa 1992).

The Cobb angle studies the entity of a scoliotic curve but is inaccurate for geometrical and statistical reasons (Beekman and Hall 1979; Robinson and Wade 1983; Bunnell 1988). It is identified by drawing two lines perpendicular to the tangents of the curve at the levels of the extreme caudal and cranial vertebral bodies. Theoretically, these lines should meet at the centre of the curve (Lusskin 1962) but because of the deformation of the vertebral bodies their angular relationships are altered and they do not do so (George and Rippstein 1961; Capusso 1981). This disparity increases as the scoliosis and degree of vertebral deformity become greater. Measurement of the Cobb angle is only related to the extreme ends of the curve and a third point is needed to define it accurately. Many statistical studies have also shown the inaccuracy of the Cobb method (Beekman and Hall 1979; Robinson and Wade 1983; Bunnell 1988). We have performed computer-assisted measurement of scoliosis using the Cobb angle but encountered a similar degree of inaccuracy as in manual measurement because of the intrinsic imprecision of this method.

We have devised a more accurate method of measurement which shows greater reproducibility (Capasso 1981, 1992).

\section{G. CAPASSO, MD}

V. TESTA, MD

II Università degli studi di Napoli

Napoli, Italy.

N. MAFFULLI, MD, MS, PhD, MIBiol, FRCS(Orth)

University of Aberdeen

Aberdeen, UK.
Beekman CE, Hall V. Variability of scoliosis measurement from spinal roentgenograms. Phys Ther 1979;59:764-5.

Bunnell WP. The natural history of idiopathic scoliosis. Clin Orthop 1988;229:20-5.

Capasso G. A new method for the radiographic evaluation of deformity in scoliosis. Ital J Orthop Traumatol 1981;7:127-36.

Capasso G. La spondilometria. Indicazioni e limiti delle misurazioni radiografiche della colonna vertebrale. Naples: Scientifiche Cuzzolin, 1992:189-313.

Capasso G, Maffulli N, Testa V. The validity and reliability of measurements in spinal deformities: a clinical appraisal. Acta Orthop Belg 1992;58:126-35.

George K, Rippstein J. A comparative study of the two popular methods of measuring scoliotic deformity of the spine. J Bone Joint Surg [Am] 1961;43-A:809-18.

Loder RT, Urquhart A, Sheen $\mathbf{H}$, et al. Variability in Cobb angle measurements in children with congenital scoliosis. J Bone Joint Surg [Br] 1995;77-B:768-70.

Lusskin R. Curves and angles: a comparison of scoliosis management. Clin Orthop 1962;23:232-5.

Robinson EF, Wade WD. Statistical assessment of two methods measuring scoliosis before treatment. Can Med Assoc J 1983;129:839-41.

Authors' reply:

Sir,

We thank Drs Capasso, Testa and Maffulli for their interesting comments. We agree with them that the methods of measurement for scoliosis are variable, inaccurate and dependent upon both geometrical and statistical concerns. Scoliosis is a complex threedimensional deformity which cannot be properly assessed by a single value such as the Cobb angle, but this method is commonly used. We set out to study the variability in measuring this angle in congenital scoliosis, not to compare the accuracy of the Cobb angle measurement with that of other methods.

Although we are not familiar with the particular method of measurement of Capasso et al we agree that more accurate and precise methods are needed. Their technique needs to be evaluated in a similar rigorous fashion as used in our study.

R. T. LODER, MD

A. URQUHART, MD

R. N. HENSINGER, MD

University of Michigan Orthopaedic Surgery

Ann Arbor

Michigan, USA. 